\title{
Suitability of Recycled PLA Filament Application in Fused Filament Fabrication Process
}

\author{
Tomislav Breški, Lukas Hentschel, Damir Godec*, Ivica Đuretek
}

\begin{abstract}
Fused filament fabrication (FFF) is currently one of the most popular additive manufacturing processes due to its simplicity and low running and material costs. Support structures, which are necessary for overhanging surfaces during production, in most cases need to be manually removed and as such, they become waste material. In this paper, experimental approach is utilised in order to assess suitability of recycling support structures into recycled filament for FFF process. Mechanical properties of standardized specimens made from recycled polylactic acid (PLA) filament as well as influence of layer height and infill density on those properties were investigated. Optimal printing parameters for recycled PLA filaments are determined with Design of Experiment methods (DOE).
\end{abstract}

Keywords: design of experiment; fused filament fabrication; polylactic acid; recycling

\section{INTRODUCTION}

Additive manufacturing (AM) is evolving on a daily basis, especially with the emphasis on low-budget market since most of the general patents related to AM technologies are expired, or are about to expire [1]. Most affordable AM machines are working on a principle of Fused Filament Fabrication (FFF) which works on a principle of material extrusion through numerically controlled nozzle [2]. One of the drawbacks of the FFF process is that it needs support material for overhanging surfaces of the model during printing. After the print job is finished, support material can be mechanically removed or dissolved with appropriate solvent, but in most cases it is mechanically removed. As such, support material if not used in any other function after removal is waste material, but due to the nature of thermoplastics primarily used in AM, it can be recycled and reused in production of new products $[3,4]$.

Polylactic acid (PLA) is one of the most widely used 3D printing filament [5]. PLA is a semi-crystalline polyester produced by fermenting under controlled conditions of a carbohydrate source, like sugarcane or corn starch. Glucose fermentation produces L-lactic acid which is a basic constituent of PLA [6]. PLA filament is cheap and in most cases it is not viable for standard user to recycle it, but with latest research in recycling processes, PLA recycling is proving more valuable than ever. Lifecycle analysis procedures related with filament recycling have shown that distributed approaches in filament recycling can further decrease filament prices without sacrificing any material properties [7]. Recycling equipment such as shredders and extruders are expensive for personal use, but with establishment of distributed centres across the countries where standard users could bring their own waste and in return buy discounted recycled filament, initial investment in recycling equipment is feasible.

Circular economy is based on regeneration of the components and the materials. By utilising of the waste material as a participant in the manufacturing process, virgin materials usage is decreased. Circular economy distinguishes two standpoints: a biological cycle, which returns the waste to natural systems, and a technical cycle, which keeps the flow of the materials in cycles which regenerate other products or systems [8]. FFF processes can be observed as circular processes, since waste materials used in the FFF process can be recycled and used for printing of new parts. Materials flow for recycled filaments for 3D printers is shown in Fig. 1.

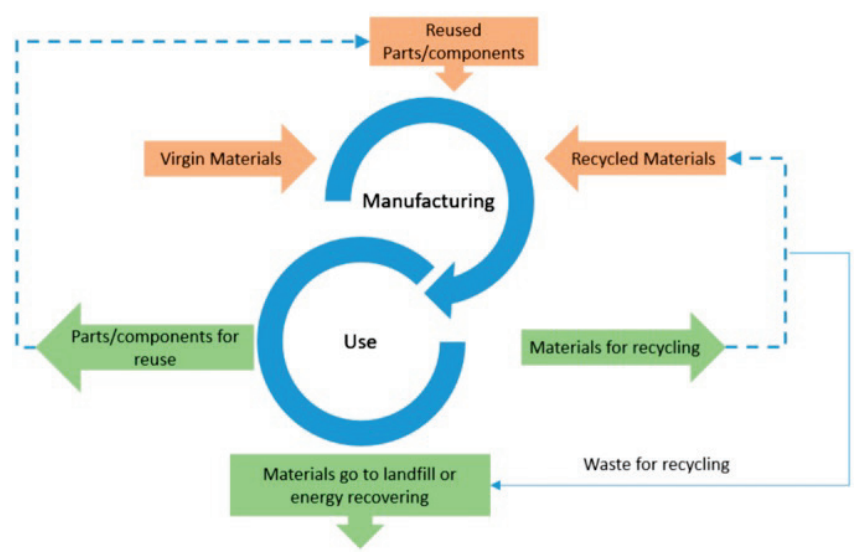

Figure 1 Materials flow for recycled filaments for 3D printers [8]

Mechanical properties of recycled filament are very dependent on number of recycling cycles [9], but with particular mixing of recycled material and virgin material, satisfactory material properties can be achieved even after 5 recycling cycles [10]. With repetitive recycling, elastic modulus of PLA remains constant, but strain at break is reduced up to $10 \%$ which needs to be taken into account. Also, rheological properties of the material tend to degrade with recycling cycles. Melt flow index (MFI) increases up to 6 times, which means that the recycled PLA filament tends to flow better with repetition of recycling cycles [11].

In order to provide a statistical background in material properties relationship with processing parameters, Design of Experiment (DoE) approaches have been used successfully in academia and industry. Processing parameters of PLA filament used on specific FFF machine can be calculated with great accuracy with modern DoE applications [12]. In this paper, DoE approach is utilised to find whether the recycled 
PLA filament is appropriate for use on low-budget FFF machines from the standpoint of accurate mechanical properties prediction. In most cases, standard users of lowbudget FFF machines change only the layer thickness and infill density in order to reduce material consumption and print time, so in this paper, these processing parameters are selected as influential parameters on measured responses of mechanical properties of dog-bone specimens, specifically tensile strength and elongation at break.

\section{MATERIALS AND METHODS \\ 2.1 Filament Production}

Recycled PLA material was produced from shredded 3D printed samples and support structures on mechanical thermoplastics shredder (SHR3D IT, 3devo B.V, Utrecht, Netherlands). Due to the nature of the mechanical grinding process, shredded PLA particles vary in size and shape since on the mentioned shredder, only one mesh size can be used. Continuous filament production was not achieved with 3DEVO filament extruder, which was meant to be used as low-budget filament production system, due to the high variation of particles shape and size. Satisfactory geometrical filament properties were achieved with a single-screw extruder (FT-E20T-MP-IS, Dr. Collin GmbH, Ebersberg, Germany) coupled with Teflon conveyor belt (GAL-25, GEPPERT-BAND GmbH, Jülich, Germany) and a selfdeveloped haul off and winding unit with processing parameters shown in Tab. 1 .

Table 1 Filament extrusion parameters

\begin{tabular}{|c|c|c|c|c|c|}
\hline$T_{1}\left({ }^{\circ} \mathrm{C}\right)$ & $T_{2}\left({ }^{\circ} \mathrm{C}\right)$ & $T_{3}\left({ }^{\circ} \mathrm{C}\right)$ & $T_{\text {nozzle }}\left({ }^{\circ} \mathrm{C}\right)$ & $\begin{array}{c}\text { Screw speed } \\
(\text { rev } / \text { min })\end{array}$ & $\begin{array}{c}\text { Pressure } \\
(\text { bar })\end{array}$ \\
\hline 195 & 200 & 205 & 205 & 100 & 120 \\
\hline
\end{tabular}

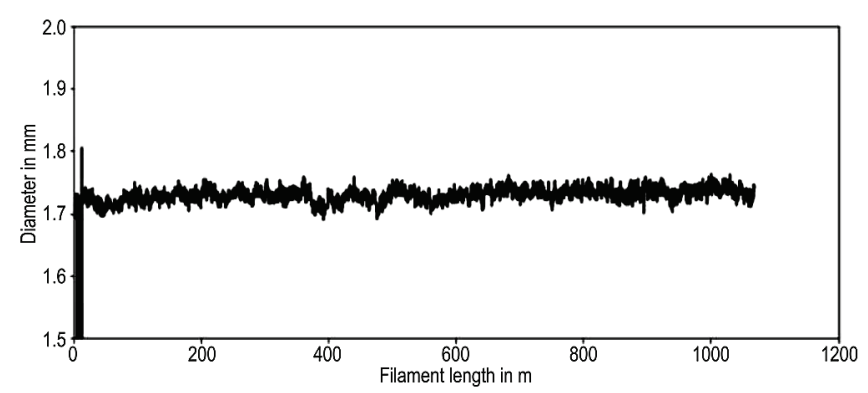

Figure 2 Diameter distribution of virgin PLA filament

During extrusion of the filaments from virgin PLA pellets and from recycled PLA shredded particles, it was observed that the recycled filament has increased variation of diameter which comes from size and shape variation of shredded PLA particles in comparison with virgin PLA pellets. Diameter distribution during extrusion of the virgin PLA filament is visible on Fig. 2, while diameter distribution during extrusion of the recycled PLA filament is visible on Fig. 4. Mean diameter of virgin PLA for the entire spool was $1,73 \mathrm{~mm}$ with standard deviation of $0,068 \mathrm{~mm}$, while mean diameter of recycled PLA for the entire spool was $1,71 \mathrm{~mm}$ with standard deviation of $0,18 \mathrm{~mm}$. Diameter histograms and ovality measurements are shown on Fig. 3 and Fig. 5.
Extrusion process got interrupted at $170 \mathrm{~mm}$ of extruded filament, but afterwards the process was continuous and filament was extruded with satisfactory geometrical properties.
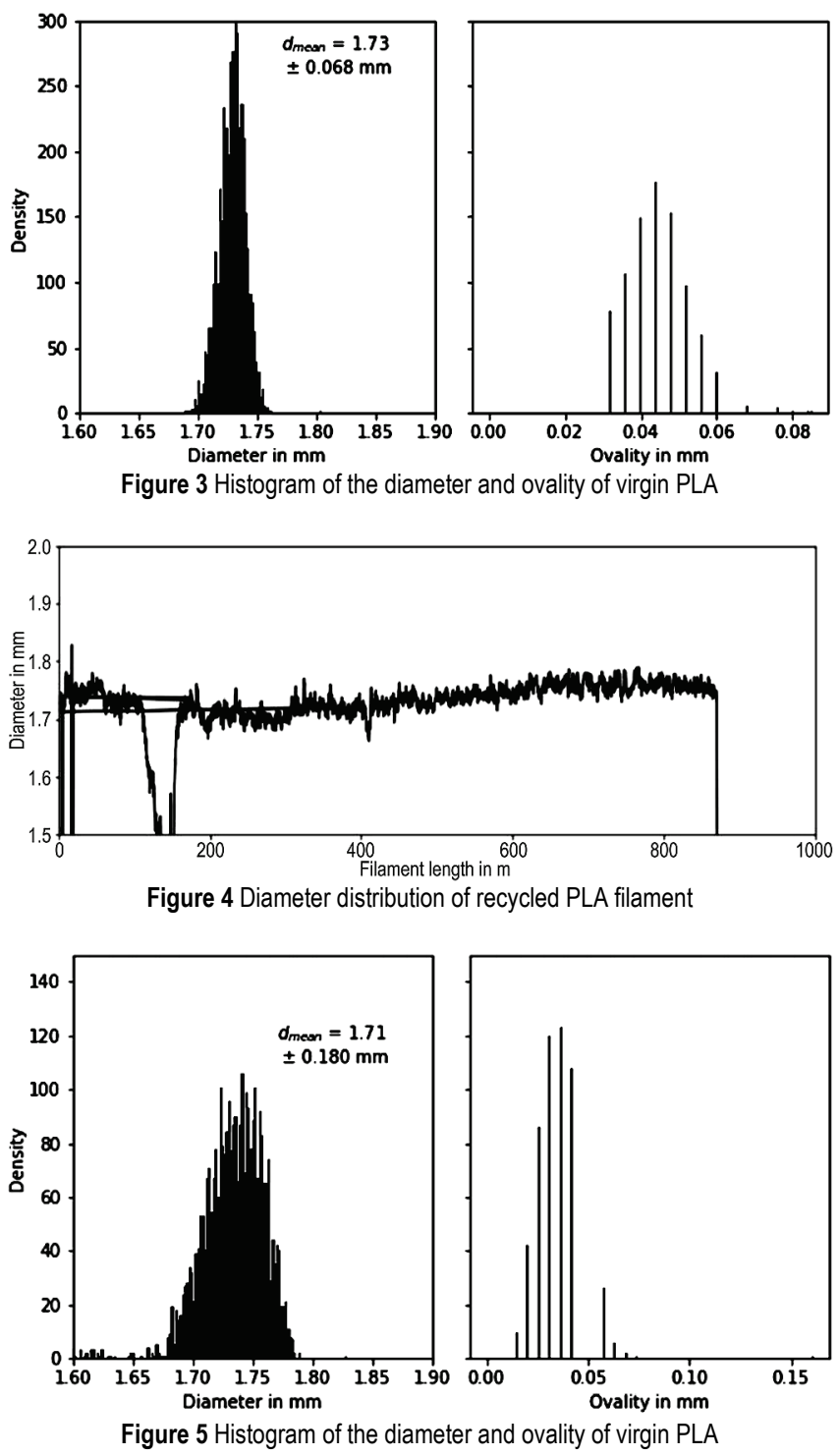

\subsection{FFF Process Parameters}

PLA filament was extruded on an Original Prusa I3 MK3S fused filament fabrication machine (Prusa Research, Prague, Czech Republic) with installed nozzle diameter of $0,4 \mathrm{~mm}$ shown in Fig. 6. Flexible PEI sheet was used as a replaceable printing surface.

The software PrusaSlicer (Prusa Research, Prague, Czech Republic) was used to prepare the G-code for dogbone specimens production with the following parameters which were kept constant through all trial runs:

- Rectilinear fill patterns for top and bottom layers

- Fill angle of $45 \%$

- Printing speed of $35 \mathrm{~mm} / \mathrm{s}$

- Extruder temperature of $210^{\circ} \mathrm{C}$

- Bed temperature of $60^{\circ} \mathrm{C}$. 


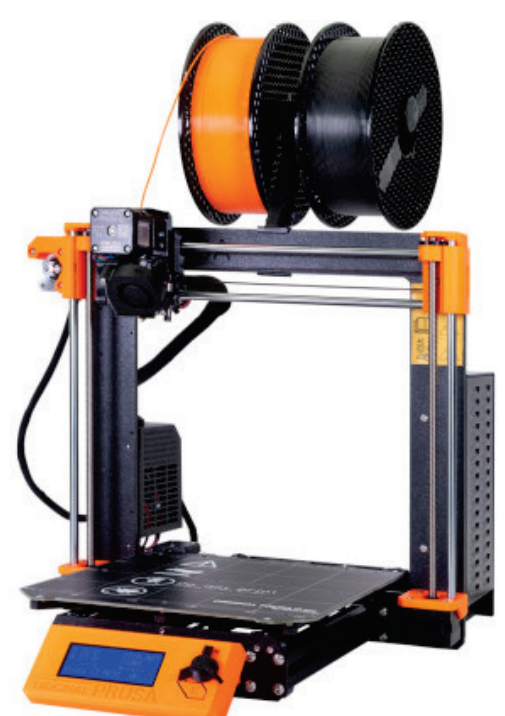

Figure 6 FFF machine Prusa I3 MK3S

Parts for tensile tests were designed as dog-bone specimens compliant with ISO 527:2019 - type A, with dimensions shown in Fig. 7.

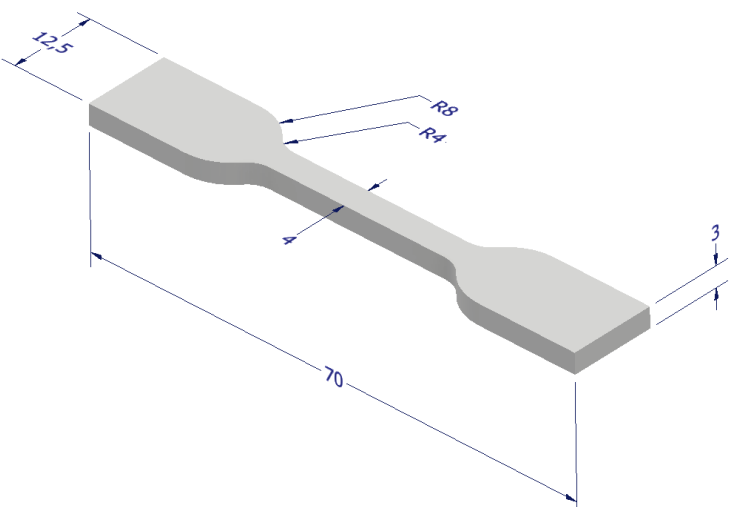

Figure 7 Dog-bone specimens for tensile testing (ISO 527:2019 - type A); dimensions in $\mathrm{mm}$

\subsection{Design of Experiment Analysis (DOE)}

For analysis of the material properties two-level factorial Design of Experiment approach was used, which allows investigation of influences of certain parameters on measured responses, which in our cases are tensile strength $(\mathrm{MPa})$ and elongation at break (\%). Design space includes two factors, which are layer height $(\mathrm{mm})$ and infill density $(\%)$, each at two levels which is visualised in Fig. 8.

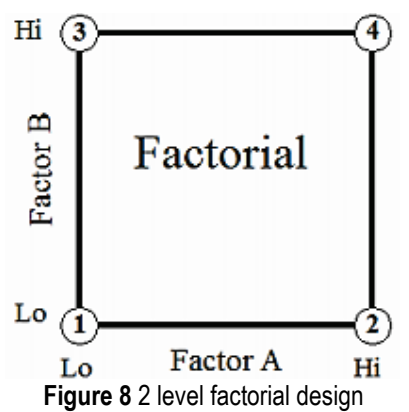

In order to increase statistical power of the design, additional points in the centre of the parameter space are added, and also 3 replicates for pure error calculation. Run list of 2 factor interaction DoE is shown in Tab. 2.

Table 22 FI DoE runs

\begin{tabular}{|c|c|c|}
\hline Run & Layer height $(\mathrm{mm})$ & Infill density (\%) \\
\hline 1 & 0,1 & 50 \\
\hline 2 & 0,2 & 30 \\
\hline 3 & 0,1 & 30 \\
\hline 4 & 0,3 & 70 \\
\hline 5 & 0,3 & 70 \\
\hline 6 & 0,3 & 50 \\
\hline 7 & 0,1 & 30 \\
\hline 8 & 0,3 & 30 \\
\hline 9 & 0,2 & 50 \\
\hline 10 & 0,3 & 30 \\
\hline 11 & 0,1 & 70 \\
\hline 12 & 0,2 & 70 \\
\hline
\end{tabular}

Three identical specimens were printed for each run, and their relative placement on the centre of the build platform is visible in Fig. 9.

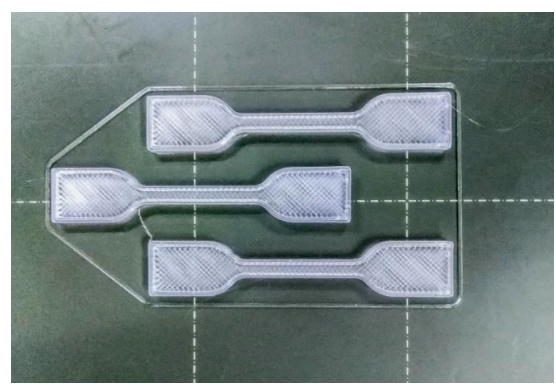

Figure 9 Printed tensile test specimens

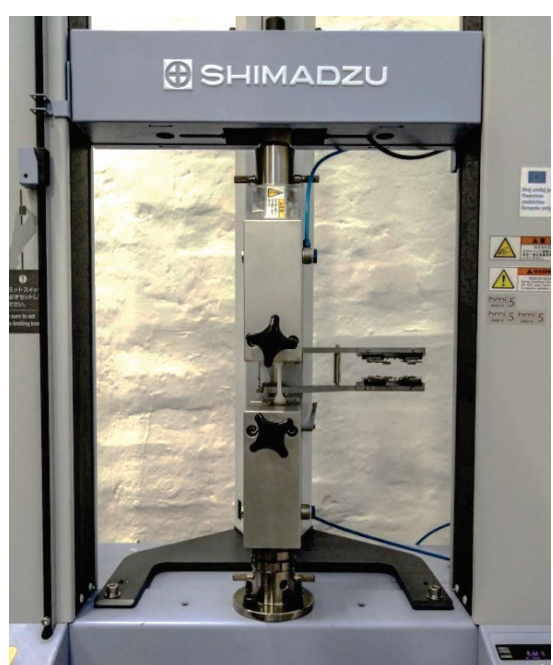

Figure 10 Shimadzu AGS-X $10 \mathrm{kN}$ with fitted dog-bone specimen

\subsection{Tensile Testing}

Tensile testing of 3D printed dog-bone specimens was performed on a universal static testing machine Shimadzu AGS-X $10 \mathrm{kN}$ fitted with contact extensometer (Shimadzu Corp., Kyoto, Japan) which is shown in Fig. 10. Tensile strength (MPa) and elongation at break (\%) was measured 
and used as characterisation parameters for the mechanical properties of the printed dog-bone specimens only from recycled PLA filament since virgin PLA filament mechanical properties are widely available and well documented in literature. Specimens were tested at deformation speed of 2 $\mathrm{mm} / \mathrm{min}$ at the temperature of $22{ }^{\circ} \mathrm{C}$, and relative humidity of $50 \%$.

During testing, specimens were breaking at the expected regions inside the extensometers which is shown in Fig. 11.

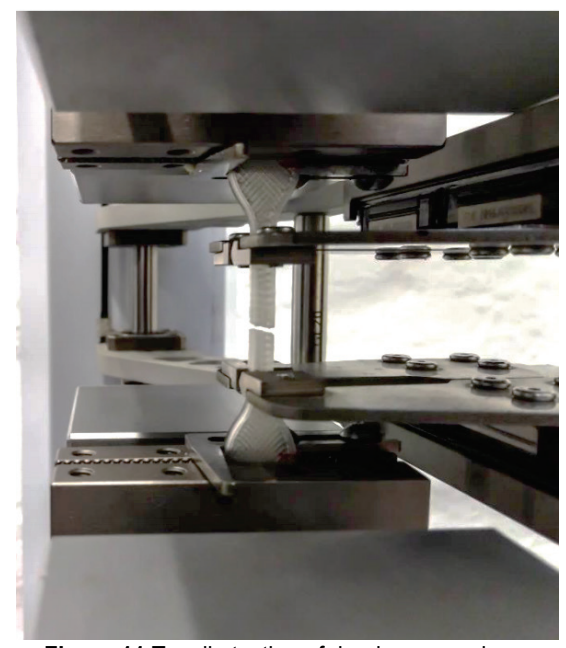

Figure 11 Tensile testing of dog-bone specimen

\section{RESULTS AND DISCUSSION}

Tensile testing results with included standard deviation (SD) of each run are shown in Tab. 3.

Table 3 Tensile testing results

\begin{tabular}{|c|c|c|}
\hline Run & Tensile strength (MPa) & Elongation at break (\%) \\
\hline 1 & $66,5 \pm 1,5$ & $6,8 \pm 1,3$ \\
\hline 2 & $59,9 \pm 3,5$ & $5,4 \pm 3,9$ \\
\hline 3 & $67,3 \pm 0,7$ & $7,2 \pm 0,5$ \\
\hline 4 & $62,2 \pm 1,1$ & $6,9 \pm 2,0$ \\
\hline 5 & $56,2 \pm 1,3$ & $6,8 \pm 0,3$ \\
\hline 6 & $56,9 \pm 1,9$ & $7,4 \pm 1,6$ \\
\hline 7 & $66,1 \pm 0,7$ & $6,3 \pm 2,3$ \\
\hline 8 & $53,4 \pm 2,6$ & $7,0 \pm 1,5$ \\
\hline 9 & $61,5 \pm 0,5$ & $7,4 \pm 2,7$ \\
\hline 10 & $55,3 \pm 1,3$ & $8,4 \pm 0,6$ \\
\hline 11 & $63,2 \pm 3,2$ & $10,4 \pm 1,7$ \\
\hline 12 & $57,1 \pm 1,7$ & $8,3 \pm 2,8$ \\
\hline
\end{tabular}

Tensile stress - strain diagram for all specimens of the DoE is shown in Fig. 12.

For statistical analysis of the tensile testing results the software Design Expert 11 (Stat - Ease Inc., Minneapolis, $\mathrm{MN}$, USA) was used. Analysis of variance (ANOVA) and response surface models were used in order to determine significance of adjustable parameters during printing of recycled PLA and their linear interactions on the observed tensile properties. Furthermore, by utilizing the statistical methods included in Design Experiment 11, mathematical functions are evaluated, which can be used for prediction of the observed tensile properties in the DoE model space.

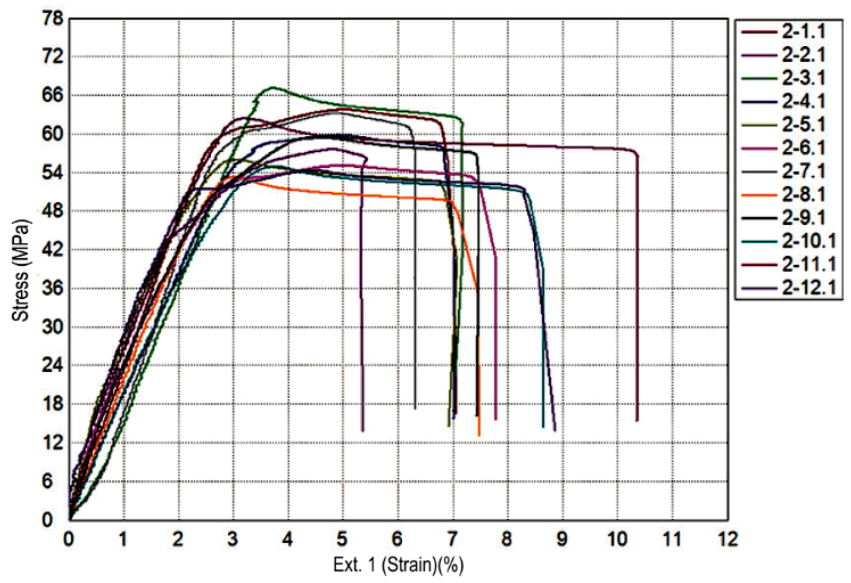

Figure 12 Tensile stress - strain diagram for all DoE runs

\subsection{Statistical Analysis of Tensile Strength Property}

Results of ANOVA for tensile strength testing are shown in Tab. 4. Based on regression analysis, mathematical model of the response surface (2FI - linear with 2 factor interaction) for tensile strength (TS) can be presented in the form of an Eq. (1), where all of the factors are in coded form which is shown also in Tab. 4.

Table 4 ANOVA for tensile strength testing (2FI model, DoF - degree of freedom)

\begin{tabular}{|c|c|c|c|c|c|c|}
\hline Source & $\begin{array}{l}\text { Sum of } \\
\text { squares }\end{array}$ & DoF & $\begin{array}{c}\text { Mean } \\
\text { square }\end{array}$ & $F$-value & $p$-value & Remark \\
\hline Model & 207,15 & 3 & 69,05 & 14,37 & 0,0014 & Significant \\
\hline $\begin{array}{c}\text { A - Layer } \\
\text { height }\end{array}$ & 148,60 & 1 & 148,60 & 30,93 & 0,0005 & Significant \\
\hline $\begin{array}{c}\text { B - Infill } \\
\text { density }\end{array}$ & 0,0486 & 1 & 0,0486 & 0,0101 & 0,9224 & \\
\hline $\mathrm{AB}$ & 31,13 & 1 & 31,13 & 6,48 & 0,0344 & Significant \\
\hline Residual & 38,44 & 8 & 4,80 & & & \\
\hline $\begin{array}{c}\text { Lack of } \\
\text { fit }\end{array}$ & 17,91 & 5 & 3,58 & 0,5236 & 0,7540 & $\begin{array}{c}\text { Not } \\
\text { significant }\end{array}$ \\
\hline Pure error & 20,53 & 3 & 6,84 & & & \\
\hline $\begin{array}{c}\text { Corrected } \\
\text { total }\end{array}$ & 245,59 & 11 & & & & \\
\hline
\end{tabular}

Tensile strength dependence on layer height and infill density can be presented in coded equation:

$$
E B=60,63-4,16 \cdot A-0,0753 \cdot B+2,17 \cdot A \cdot B .
$$

By observing the Tab. 4 it is visible that the model is significant, which means that the appropriate statistical model is selected and that the model is accurately predicting the tensile strength in the model space. Lack of fit is not significant relative to the pure error which also gives the information that the model is satisfactory inside model parameter space. By increasing the layer height tensile strength is reduced because the A coefficient in the coded Eq. (1) is negative and from ANOVA, $A$ coefficient is significant. Also, interaction of layer height and infill density is significant, which positively influences on tensile strength. Tensile strength response surface is shown in Fig. 13.

Influence of infill density and layer height on tensile strength is shown in Fig. 14 


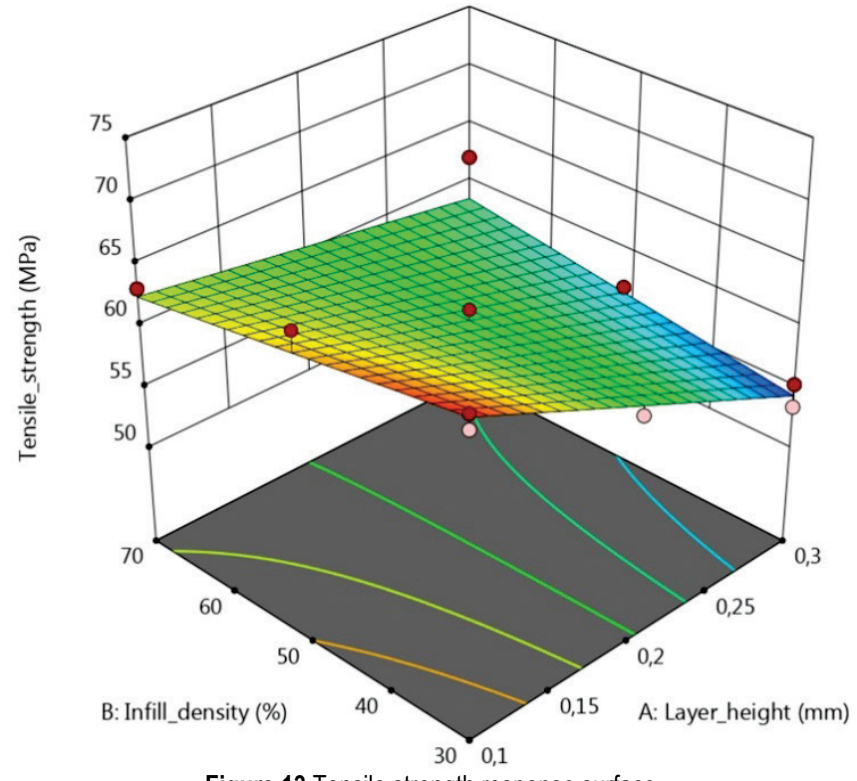

Figure 13 Tensile strength response surface

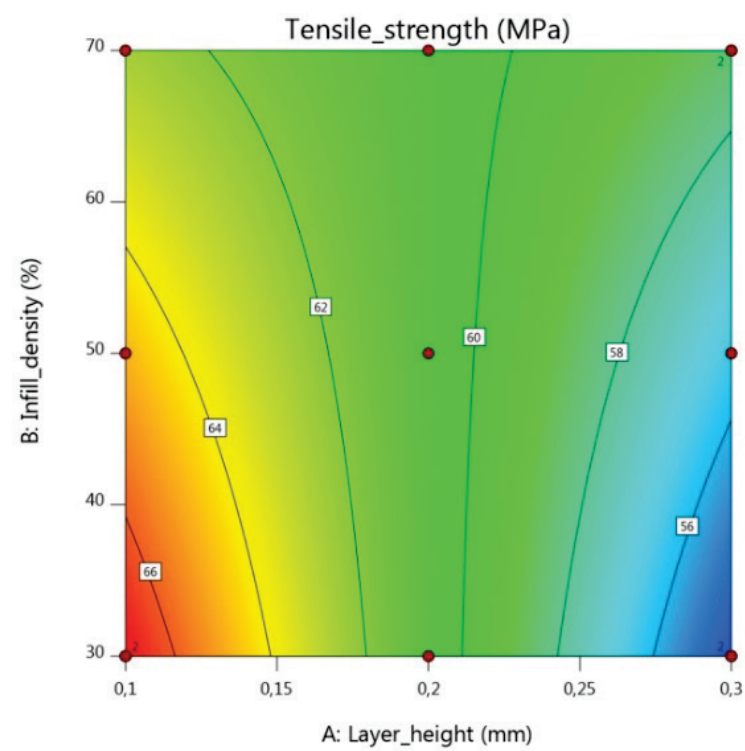

Figure 14. Influence of infill density and layer height on tensile strength

As it can be seen from Fig. 14, the most significant factor on tensile strength is layer height, where maximum tensile strength can be obtained with minimum layer height. Smaller layer height means that better inter-layer bonding can be accomplished and the result is increasing of tensile strength of the specimens. Although infill density is not significant factor, it contributes through interaction with layer height with positive influence.

\subsection{Statistical Analysis of Elongation at Break}

Results of ANOVA for elongation at break testing are shown in Tab. 5. Based on regression analysis, mathematical model of the response surface (2FI) for elongation at break (EB) can be presented in the form of an Eq. (2), where all of the factors are in coded form which is shown also in Tab. 5.
Table 5 ANOVA for elongation at break testing (2FI model, DoF - degree of

\begin{tabular}{|c|c|c|c|c|c|c|}
\hline Source & $\begin{array}{c}\text { Sum of } \\
\text { squares }\end{array}$ & DoF & $\begin{array}{c}\text { Mean } \\
\text { square }\end{array}$ & $F$-value & $p$-value & Remark \\
\hline Model & 11,16 & 3 & 3,72 & 4,95 & 0,0394 & Significant \\
\hline $\begin{array}{c}A-\text { Layer } \\
\text { height }\end{array}$ & 1,35 & 1 & 1,35 & 1,80 & 0,2162 & \\
\hline $\begin{array}{c}B-\text { Infill } \\
\text { density }\end{array}$ & 5,32 & 1 & 5,32 & 7,07 & 0,0288 & Significant \\
\hline$A \cdot B$ & 7,26 & 1 & 7,26 & 9,66 & 0,0145 & Significant \\
\hline Residual & 6,01 & 8 & 0,7514 & & & $\begin{array}{c}\text { Not } \\
\text { significant }\end{array}$ \\
\hline $\begin{array}{c}\text { Lack of fit } \\
4,62\end{array}$ & 5 & 0,9242 & 1,99 & 0,3023 & \\
\hline Pure error & 1,39 & 3 & 0,4633 & & & \\
\hline $\begin{array}{c}\text { Corrected } \\
\text { total }\end{array}$ & 17,17 & 11 & & & & \\
\hline
\end{tabular}

Elongation at break coded equation:

$$
E B=7,54-0,3977 \cdot A+0,7877 \cdot B+1,05 \cdot A \cdot B .
$$

By observing the Tab. 5 it is visible that the model is significant, which means that the appropriate statistical model is selected and that the model is accurately predicting the elongation at break in the model space. Lack of fit is not significant relative to the pure error which also gives the information that the model is satisfactory inside model parameter space. From ANOVA analysis it can be concluded that significant factor in this case is infill density, and interaction between infill density and layer height.

By increasing the infill density, elongation at break is also increased, while interaction between both parameters has opposite influence on elongation at break. Elongation at break response surface is shown in Fig. 15.

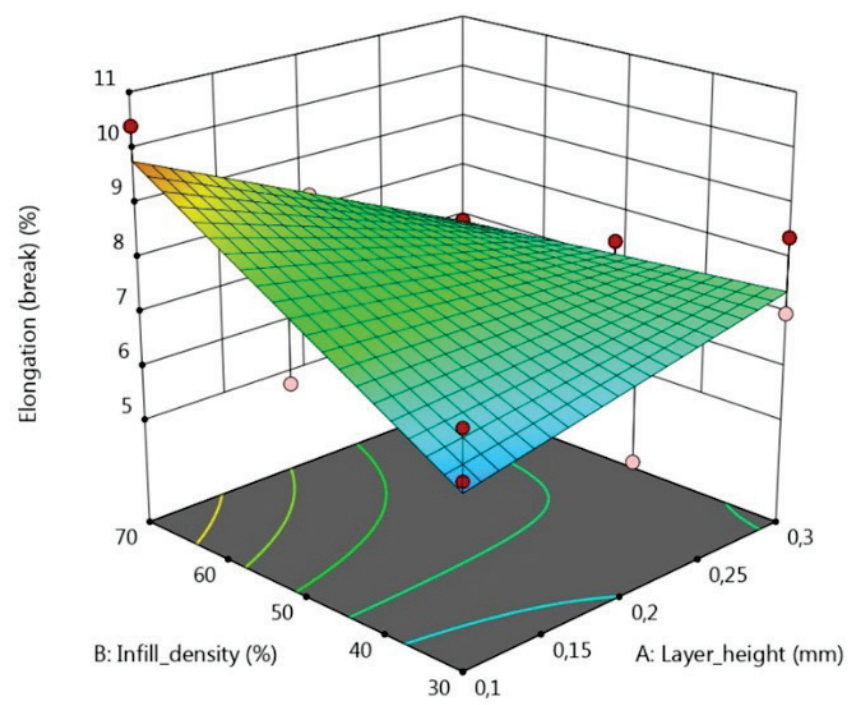

Figure 15 Elongation at break response surface

Influence of infill density and layer thickness on elongation at break is shown in Fig. 16.

In case of influence of infill density on elongation at break, it can be concluded, that with lower density, more brittle break will be present. In both cases, there more complex influence is present through interaction between both parameters, which is especially obvious in case of 
elongation at break, where interaction is the most significant factor with positive influence on elongation at break (Eq. (2)).

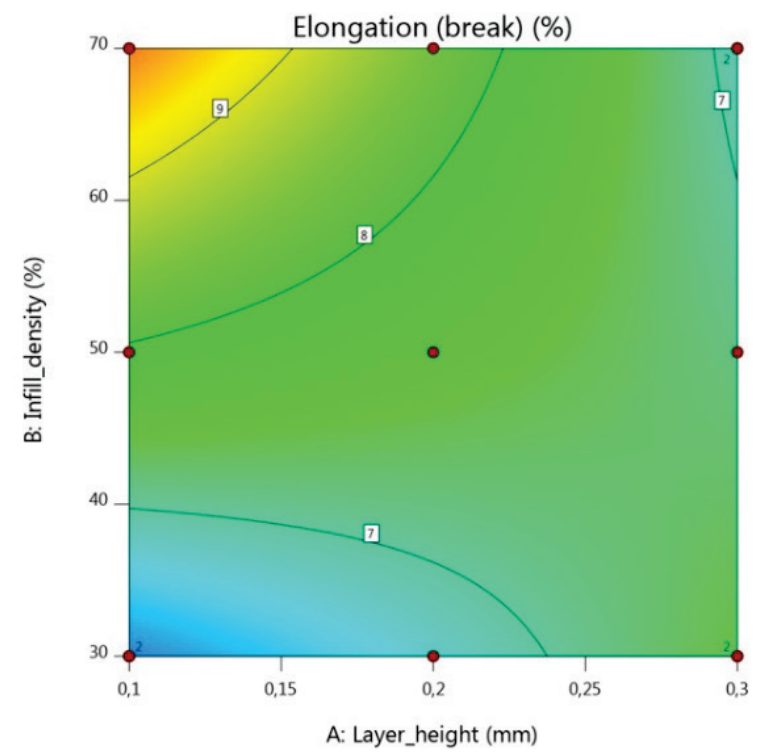

Figure 16 Influence of infill density and layer height on elongation at break

Unexpected result in this research is that infill density has almost no influence on tensile strength, or even negative influence in case of minimum layer height. Therefore this behaviour of specimens produced from recycled PLA has to be more investigated.

\section{CONCLUSION}

In this research DoE approach was utilised in order to assess suitability of recycled PLA filament usage in lowbudget fused filament forming processes. Results have shown that the models are significant, and in correlation with already done research. Due to particle shape and size variation in shredded PLA material, low-budget filament extruders are not yet suitable for general use, so filament recycling is still not available to most of the users which use low-budget fused filament forming 3D printers. Filament produced on industrial grade extruder from virgin PLA material has satisfactory geometrical and mechanical properties, and can be used on low-budget FFF printers without any issues during printing, while filament produced from recycled PLA material has increased diameter variation which can lead to potential clogging during printing on lowbudget FFF machines. The industry of filament recycling has great potential and is yet to be more explored especially in areas of filament dimensional stability and mechanical properties repeatability. Potential establishment of distributed centres for 3D printing waste material recycling is very promising and is yet to be adopted by industry worldwide.

\section{Acknowledgements}

This paper is part of the research included in project Increasing Excellence on Advanced Additive Manufacturing. This project has received funding from the
European Union's Horizon 2020 research and innovation programme under grant agreement No 810708 . The authors would like to thank the EU for the financing of the project and Lehrstuhl KV at Montanuniversity in Leoben for support in filament production.

\section{Notice}

The paper was presented at MOTSP $2021-12^{\text {th }}$ International Conference Management of Technology - Step to Sustainable Production, which took place in Poreč/Porenzo, Istria (Croatia), on September 8-10, 2021. The paper will not be published anywhere else.

\section{REFERENCES}

[1] Gebler, M., Schoot Uiterkamp, A. J. M., \& Visser, C. (2014). A global sustainability perspective on $3 \mathrm{D}$ printing technologies. Energy Policy, 74, 158-167. https://doi.org/10.1016/j.enpol.2014.08.033

[2] Diegel, O., Nordin, A., \& Motte, D. (2020). A Practical Guide to Design for Additive Manufacturing. Springer Series in Advanced Manufacturing. Springer, $246 \mathrm{p}$. https://doi.org/10.1007/978-981-13-8281-9

[3] Beltrán, F. R., et al. (2021). Technical evaluation of mechanical recycling of PLA 3D printing wastes. Polymers (Basel), 13(8). https://doi.org/10.3390/polym13081247

[4] Hong, J. H., Yu, T., Park, S. J., \& Kim, Y. H. (2020). Repetitive recycling of 3D printing PLA filament as renewable resources on mechanical and thermal loads. Int. J. Mod. Phys. B, 34(2224), 1-5. https://doi.org/10.1142/S0217979220401475

[5] Ngo, T. D., Kashani, A., Imbalzano, G., Nguyen, K. T. Q., \& Hui, D. (2018). Additive manufacturing (3D printing): A review of materials, methods, applications and challenges. Compos. Part B Eng., 143, 172-196. https://doi.org/10.1016/j.compositesb.2018.02.012

[6] Madhavan Nampoothiri, K., Nair, N. R., \& John, R. P. (2010). An overview of the recent developments in polylactide (PLA) research. Bioresour. Technol., 101(22), 8493-8501. https://doi.org/10.1016/j.biortech.2010.05.092

[7] Baechler, C., Devuono, M., \& Pearce, J. M. (2013). Distributed recycling of waste polymer into RepRap feedstock. Rapid Prototyp. J., 19(2), 118-125. https://doi.org/10.1108/13552541311302978

[8] Muñoz, V., Martínez, L., Carrasco-Gallego, R., de Juanes Marquez, J. \& Hidalgo-Carvajal, D. (2020). Evaluation of the Circularity of Recycled PLA Filaments for 3D Printers. Applied Sciences, 10(24), 8967. https://doi.org/10.3390/app10248967

[9] Chiu, H. T., Huang, J. K., Kuo, M. T., \& Huang, J. H. (2018). Characterisation of $\mathrm{PC} / \mathrm{ABS}$ blend during 20 reprocessing cycles and subsequent functionality recovery by virgin additives. J. Polym. Res., 25(5). https://doi.org/10.1007/s10965-018-1522-6

[10] Babagowda, Kadadevara Math, R. S., Goutham, R., \& Srinivas Prasad, K. R. (2018). Study of Effects on Mechanical Properties of PLA Filament which is blended with Recycled PLA Materials. IOP Conf. Ser. Mater. Sci. Eng., 310(1). https://doi.org/10.1088/1757-899X/310/1/012103

[11] Cruz Sanchez, F. A., Boudaoud, H., Hoppe, S., \& Camargo, M. (2017). Polymer recycling in an open-source additive manufacturing context: Mechanical issues. Addit. Manuf., 17, 87-105. https://doi.org/10.1016/j.addma.2017.05.013 
[12] Lanzotti, A., Martorelli, M., \& Staiano, G. (2015). Understanding Process Parameter Effects of RepRap OpenSource Three-Dimensional Printers through a Design of Experiments Approach. J. Manuf. Sci. Eng. Trans. ASME, 137(1), 1-8. https://doi.org/10.1115/1.4029045

\section{Authors' contacts:}

Tomislav Breški, mag. ing. mech.

University of Zagreb,

Faculty of Mechanical Engineering and Naval Architecture,

Ivana Lucica 5, 10000 Zagreb, Croatia

+38516168338, tomislav.breski@fsb.hr

Lukas Hentschel, dipl. ing.

Montanuniveristät Leoben,

Chair of Polymer Processing,

Otto Glöckel-Straße 2, 8700 Leoben, Austria

+4338424023506, lukas.hentschel@unileoben.ac.at

Damir Godec, prof. dr. sc., dipl. Ing.

(Corresponding author)

University of Zagreb,

Faculty of Mechanical Engineering and Naval Architecture,

Ivana Lucica 5, 10000 Zagreb, Croatia

+38516168192, damir.godec@fsb.hr

Ivica Đuretek, Dr. mont., dipl. ing.

Montanuniveristät Leoben,

Chair of Polymer Processing,

Otto Glöckel-Straße 2, 8700 Leoben, Austria

+4338424023518, Ivica.Duretek@unileoben.ac.at 